Optom Vis Sci. 2009 June ; 86(6): 624-628. doi:10.1097/OPX.0b013e3181a6a225.

\title{
Treatment Options for Myopia
}

\author{
Jane Gwiazda, PhD, FAAO \\ The New England College of Optometry, Boston, Massachusetts
}

\begin{abstract}
Myopia is a significant public health problem and its prevalence may be increasing over time. The main treatment options of single vision spectacle lenses, contact lenses, and refractive surgery do not slow the accompanying eye growth or retard the physiological changes associated with excessive axial elongation. High myopia is a predisposing factor for retinal detachment, myopic retinopathy, and glaucoma, contributing to loss of vision and blindness. The high prevalence of myopia and its prominence as a public health problem emphasize the importance of finding effective treatments that slow myopia progression and axial elongation. Treatments that have been investigated include various types of spectacle lenses and contact lenses, as well as pharmaceutical agents such as atropine and pirenzepine. The bulk of evidence from well-conducted studies shows that overall, most therapies for myopia have small treatment benefits that last for a relatively short period of time or have significant side effects. Some therapies may be more effective in subsets of myopic children. This review of treatment options for myopia will emphasize recent results from well-designed clinical studies and will suggest possible future therapies.
\end{abstract}

\section{Keywords}

myopia; refractive error; refractive correction; children's vision

\begin{abstract}
Myopia is a significant public health problem, affecting 33\% of individuals over the age of 12 years in the United States ${ }^{1}$ and a much higher percentage in parts of Asia such as Taiwan and Singapore, ${ }^{2,3}$ and the prevalence may be increasing over time. ${ }^{4,5}$ Single vision spectacle lenses and contact lenses are commonly prescribed for myopia and more recently refractive surgery has become a popular option. While these treatments correct the myopic refractive error, they do not slow the accompanying eye growth or retard the physiological changes associated with excessive axial elongation (reviewed in ${ }^{6}$ ). The World Health Organization has set a goal to eliminate preventable blindness in the world by the year 2020, with refractive error, including myopia, as one of its top five priorities. ${ }^{7}$ The high prevalence of myopia and its prominence as a public health problem emphasize the importance of gaining increased understanding of the mechanisms of eye growth and of finding effective treatments that slow progression and axial elongation.
\end{abstract}

\section{Treatments to Slow the Progression of Myopia}

Treatments that are currently available for slowing the progression of myopia include spectacle lenses, contact lenses, and pharmaceutical agents. Many of the intervention studies evaluating these treatments have had methodological limitations, and their results should be interpreted with caution. In order for results to be given serious consideration, the treatment trial should include the following features: a concurrent control group, random assignment to the treatment 
and control groups, masking of investigators who collect the outcome data, standardized measurements, a large enough sample size, and a small loss to follow-up. The bulk of evidence from well-designed studies with proper controls shows that most therapies for myopia have small treatment benefits that last for a relatively short period of time or have significant side effects. This review of treatment options for myopia will emphasize recent results from welldesigned clinical studies.

\section{Single Vision Lenses}

An active emmetropization mechanism regulated by optical defocus is supported by results of numerous studies (reviewed in ${ }^{8}$ ). Strong evidence is provided by compensatory ocular growth seen in response to lens-induced defocus in animal models. ${ }^{9}$ Based on these results, it has been suggested that spectacle intervention in myopic children with the commonly prescribed single vision lenses (SVLs) might lead to increased progression and axial elongation. Patterns of lens wear in myopic patients can vary from full-time wear, to the use of lenses for distance viewing only, to non-wear of prescribed lenses. Limited data are available on myopia progression by pattern of lens wear, though pilot data suggest that progression is similar for the different patterns. ${ }^{10}$ Additional investigation using a large sample of children randomly assigned to a lens wear regimen is warranted.

Under-correction of myopia with SVLs is a treatment option advocated by some clinicians. Only one masked, randomized clinical trial has been conducted to evaluate this treatment. ${ }^{11}$ Ninety-four of 106 (89\%) myopic children aged 9-14 years completed two years of spectacle wear in SVLs, half randomized to full correction and half to under-correction by approximately $0.75 \mathrm{D}$. Two-year progression in the fully corrected group was $0.77 \mathrm{D}$, significantly less than the 1.0 D in the under-corrected group $(\mathrm{p}<0.01)$. This finding was unexpected, based on the results from animal studies discussed above, and more research is needed.

\section{Bifocals and Progressive Addition Lenses}

The use of bifocals or progressive addition lenses (PALs), sometimes called no-line bifocals, for slowing the progression of myopia has produced relatively small treatment effects overall, on the order of 0.15 to $0.50 \mathrm{D}$ over 1.5 to 3 years, ${ }^{12-17}$ although treatment effects are reported to be larger in certain subgroups of myopic children, as described below.

The largest of the treatment trials with this type of lens was the Correction of Myopia Evaluation Trial (COMET), a multi-center, randomized, double-masked clinical trial to evaluate whether PALs slow the rate of progression of myopia compared to conventional SVLs. ${ }^{15}$ COMET enrolled 469 children aged $6-11$ years who were ethnically diverse (46\% white, 26\% AfricanAmerican, $14 \%$ Hispanic, and 8\% Asian) and had baseline myopia between $-1.25 \mathrm{D}$ and -4.50 D. The primary outcome measure was progression of myopia by cycloplegic autorefraction with tropicamide. Retention was excellent, with $462 / 469$ (98.5\%) of the children completing the three-year visit. Adjusted mean myopia increased from baseline to 3 years by $1.28 \pm 0.06$ $\mathrm{D}$ in the PAL group and $1.48 \pm 0.06 \mathrm{D}$ in the SVL group. The overall adjusted 3-year treatment effect of $0.20 \pm 0.08 \mathrm{D}$ was statistically significant $(\mathrm{p}=0.004)$ but not clinically meaningful. All of the treatment effect occurred in the first year. Additional analyses showed that there were significant 3-year treatment effects in children with larger lags of accommodation in combination with near esophoria $(0.64 \mathrm{D} \pm 0.21)$, shorter reading distances $(0.44 \mathrm{D} \pm 0.20)$, or lower baseline myopia $(0.48 \mathrm{D} \pm 0.15)$ that became larger from 1 to 3 years of follow-up. ${ }^{16}$ These results support a role for retinal defocus in myopia progression and suggest that myopic children with large accommodative lags and near esophoria may benefit from wearing PALs. The COMET2 study is presently underway to evaluate PALs vs. SVLs for slowing myopia progression in children with these characteristics. 
Recently, a study similar to COMET was conducted in Japan. ${ }^{17}$ A unique feature of this investigation of PALs vs. SVLs for slowing myopia progression in 6-12 year old children was the use of a crossover design. Children with myopia from -1.25 to $-6.0 \mathrm{D}$ were randomly chosen to wear one type of spectacle lens for the first half of the study, and then midway through the 3-year period of follow-up they were switched to the other eyeglass type. Results showed a statistically significant treatment benefit of PALs vs SVLs of $0.17 \mathrm{D}$ at 18 months. At the end of the second 18-month period, after children wore the other lens type, progression in the group wearing PALs first was 0.29 D less than in the group with SVLs first, leading to the suggestion that early intervention with PALs may work better than SVLs in this age and refractive error range. As in COMET, children with larger accommodative lags had a larger treatment effect than those with smaller lags $(0.61 \mathrm{D}$ vs. $0.15 \mathrm{D})$, and children who were esophoric or orthophoric at near had a larger treatment effect than those who were more exophoric (0.55 D vs. $0.18 \mathrm{D})$.

\section{Contact Lenses}

Many early investigations of rigid gas permeable contact lenses (RGP) for myopia control suffered from lack of randomization and a high drop out rate from the contact lens group. ${ }^{18}$, ${ }^{19}$ In an attempt to eliminate the high loss to follow-up found in previous studies, a recent randomized clinical trial, the Contact Lens and Myopia Progression (CLAMP) study, implemented a run-in period to ensure good compliance with rigid contact lens wear. ${ }^{20}$ One hundred and sixteen children who successfully completed the run-in period were randomized to wear either RGP or soft contact lenses for three years. Results showed a statistically significant difference in 3-year myopia progression in the RGP vs. soft lens group $(-1.56 \pm$ $0.95 \mathrm{D}$ for RGP wearers vs. $-2.19 \pm 0.89 \mathrm{D}$ for the soft lens group, $\mathrm{p}<0.001)$. Most of the slowed progression with RGP lenses was found in the first year. Corneal curvature steepened significantly less over three years in the RGP group $(0.62 \pm 0.60 \mathrm{D}$ compared to the soft lens group $(0.88 \pm 0.57 \mathrm{D}, \mathrm{p}=0.01)$, again with most of the difference found in the first year. Threeyear axial elongation was not significantly different between treatment groups. These results, taken together, suggest that the slowed myopia progression was mainly due to corneal flattening, which may be reversible with discontinuation of RGP lens wear. In the absence of differences in axial elongation and with most of the treatment effect occurring in the first year, the authors of the CLAMP study concluded that RGP lenses should not be prescribed mainly for myopia control.

The Longitudinal Orthokeratology Research in Children (LORIC) was a pilot study conducted in Hong Kong to determine if overnight wear of specially designed RGP contact lenses slowed axial elongation and the progression of myopia. ${ }^{21}$ Thirty-five children wore these lenses for two years, and their results were compared to those from an historical control group of children wearing SVLs. Change in axial length rather than refractive error is typically used as the outcome measure because of corneal flattening produced by the lenses. Results of the study showed that over the 2-year period axial length in the orthokeratology group increased by 0.29 $\mathrm{mm}$ vs. $0.54 \mathrm{~mm}$ for the control group, a significant difference. A well-designed study on what is now called corneal refractive therapy with sufficient subject numbers and random assignment still needs to be conducted to more fully evaluate this type of treatment for slowing myopia progression.

Anecdotal reports and evidence from pilot studies have suggested that the use of soft contact lenses speeds up myopia progression. ${ }^{22}$ However, a recent randomized trial investigating the effect of soft contact lenses on myopia progression in children reported no significant difference in progression between soft contact lens and spectacle wearers. ${ }^{23}$ 


\section{Pharmaceutical Agents}

Atropine-Recent well-designed studies using topical atropine, a non-selective muscarinic antagonist, have demonstrated statistically and clinically significant reductions in the progression of myopia. ${ }^{24,25}$ Shih et al ${ }^{24}$ reported that myopia progression was significantly slowed ( $\mathrm{p}<0.0001$ )over 18 months in 6-13 year old children randomized to $0.5 \%$ atropine with multi-focal glasses $(0.41 \mathrm{D})$ compared to multi-focal glasses alone $(1.19 \mathrm{D})$ or SVLs alone $(1.40 \mathrm{D})$. Chua et al ${ }^{25}$ reported similar results in a two-year study of 400 6-12 year-old myopic children in Singapore, although this study used a different experimental paradigm. Children were randomly assigned to either the atropine or the placebo-control group, with only one eye of each child treated with either $1 \%$ atropine or vehicle eye drops once nightly. Two-year progression in the atropine-treated eyes was found to be $-0.28 \mathrm{D}$, significantly less than progression in the control eyes $(-1.20 \mathrm{D})$. Myopia progression in the untreated eyes of both groups was similar to that of the control eyes. This outcome meant that many of the children in the atropine group were effectively anisometropic at the end of the study. The study did not report follow-up data to indicate whether a rebound effect (increased progression in the atropine-treated eyes after cessation of treatment) might have occurred. A new clinical trial is currently underway in Singapore that evaluates different concentrations of atropine applied to both eyes and that also will measure progression of myopia after treatment is stopped. Although atropine is used in many countries in Asia for slowing the progression of myopia, it is rarely used in the United States for this purpose. The side effects associated with atropine (e.g., photophobia, cycloplegia) are considered by many clinicians to be unacceptable for long-term therapy.

Pirenzepine-Pirenzepine, like atropine, is a muscarinic antagonist but it is less likely to produce mydriasis and cycloplegia. Two clinical trials of pirenzepine have been conducted, one in Singapore, Hong Kong, and Thailand ${ }^{26}$ and the other in the United States. ${ }^{27-28}$ In the Singapore study, myopia in children increased over a one-year period by $0.47 \mathrm{D}$ for those using pirenzepine ophthalmic gel twice a day, $0.70 \mathrm{D}$ for those using it once a day, and $0.84 \mathrm{D}$ for the control group. ${ }^{26}$ In the U.S. study, myopia increased over one year by $0.26 \mathrm{D}$ in the pirenzepine group (used once a day) and $0.53 \mathrm{D}$ in the control group. ${ }^{27}$ Recently, two-year data from the same study were published, showing an increase in the size of the treatment effect from 0.30 to 0.41 between one and two years. ${ }^{28}$ However, these results from the U.S. study must be interpreted with caution since the study was designed as a one-year study and only 84 of the originally enrolled 174 subjects (48\%) agreed to continue for a second year.

\section{Issues to Consider in Evaluating Treatments for Myopia}

Many of the studies summarized above show statistically significant differences between experimental and control treatments for slowing the progression of myopia, but most of the results are not considered to be clinically meaningful. In part that is because many of the treatments are effective early on, but after the initial months the treatment effects may increase only minimally or not at all. As shown in Table 1, the limited increases in treatment effects are found for both lens and drug treatments. Possible solutions to this problem include switching from one treatment to another when the first one no longer slows myopia progression, combining treatments, or introducing periods of time (hours, days, or weeks) without any treatment.

Another reason why treatments may show limited benefits is because inclusion criteria for the clinical trials typically are quite broad, and all treatments, especially lenses, are not likely to work for all myopes. It may be helpful to take into account factors such as the amount of myopia, oculomotor characteristics (e.g., accommodation, phoria), and parental refractive state when considering treatment options for a particular patient. For example, COMET showed that 
PALs were more effective than SVLs in children with low myopia, large accommodative lags, and two myopic parents. $15,16,29$

Eventually, if a treatment is found to slow progression for longer than a year and with minimal side effects, then it would be beneficial to consider using that therapy for a child at risk for the development of myopia. However, at this time we cannot identify with certainty an at-risk child likely to develop myopia. A refractive error of less than $+0.75 \mathrm{D}$ in the early school years has been found to be an important risk factor for myopia development in the pre-teen and early teen years. ${ }^{30,31}$ Using a cutoff of a spherical equivalent refraction of less than $+0.75 \mathrm{D}$ in the third grade (average age of 8.6 years), Zadnik et al reported a sensitivity of $86.7 \%$ and a specificity of $73.3 \%$ for developing myopia in grades $4-8 ; 45$ of 554 children (8\%) became myopic in that time. ${ }^{31}$ The paper concluded that "this level of performance does not have the high level of both sensitivity and specificity needed to made decisions regarding which particular child should receive any potential treatment," which is a fair assessment. Therefore, at this time it is difficult to justify the cost and possible side effects of treatment for a child who may never develop myopia.

Another concern is whether non-myopic children will comply with a treatment. For example, will they wear lenses if they do not need them to see clearly? Will they use eye drops every day if there are side effects such as blurry vision or photophobia? On the other hand, children and their parents might be more motivated to comply with a treatment if they knew it could stop myopia from developing rather than just slow down progression in already myopic eyes.

\section{Possible Future Treatments}

Treatment options not previously discussed and likely to hold promise are correction of peripheral ametropia/aberrations and provision of extensive outdoor activity. Recent animal work has suggested that visual signals from the fovea may not be essential for normal eye growth since the peripheral retina appears to be able to regulate emmetropization and induce myopia in response to abnormal visual input. ${ }^{32}$ Correction of peripheral ametropia/aberrations may be achieved by specially designed contact lenses worn during the day or by orthokeratology. Multiple investigations of these treatment options are presently underway.

One of the simplest therapies for retarding myopia, yet to be tested in a rigorous study, could turn out to be providing children with substantial hours of outdoor activity each week, though much more needs to be learned about possible underlying mechanisms. Several large studies conducted in different parts of the world have reported that the prevalence of myopia in children with more outdoor activity hours is lower than in children with fewer hours. ${ }^{33-36}$ It appears that being outdoors is more important than being active since no association has been reported between indoor sports and myopia. ${ }^{33}$ Eventually a clinical trial evaluating outdoor activity as a possible therapy for myopia may be conducted, but this effort should wait until more is known about the source of the protective effect.

\section{ACKNOWLEDGMENTS}

Supported by NEI/NIH grant EY11756.

\section{REFERENCES}

1. Vitale S, Ellwein L, Cotch MF, Ferris FL 3rd, Sperduto R. Prevalence of refractive error in the United States, 1999-2004. Arch Ophthalmol 2008;126:1111-9. [PubMed: 18695106]

2. Lin LL, Shih YF, Tsai CB, Chen CJ, Lee LA, Hung PT, Hou PK. Epidemiologic study of ocular refraction among schoolchildren in Taiwan in 1995. Optom Vis Sci 1999;76:275-81. [PubMed: 10375241] 
3. Saw SM. A synopsis of the prevalence rates and environmental risk factors for myopia. Clin Exp Optom 2003;86:289-94. [PubMed: 14558850]

4. The Framingham Offspring Eye Study Group. Familial aggregation and prevalence of myopia in the Framingham Offspring Eye Study. Arch Ophthalmol 1996;114:326-32. [PubMed: 8600894]

5. Morgan I, Rose K. How genetic is school myopia? Prog Retin Eye Res 2005;24:1-38. [PubMed: 15555525]

6. Saw SM, Gazzard G, Shih-Yen EC, Chua WH. Myopia and associated pathological complications. Ophthalmic Physiol Opt 2005;25:381-91. [PubMed: 16101943]

7. Dandona R, Dandona L. Refractive error blindness. Bull World Health Organ 2001;79:237-43. [PubMed: 11285669]

8. Wallman J, Winawer J. Homeostasis of eye growth and the question of myopia. Neuron 2004;43:44768. [PubMed: 15312645]

9. Hung LF, Crawford ML, Smith EL 3rd. Spectacle lenses alter eye growth and the refractive status of young monkeys. Nat Med 1995;1:761-5. [PubMed: 7585177]

10. Ong E, Grice K, Held R, Thorn F, Gwiazda J. Effects of spectacle intervention on the progression of myopia in children. Optom Vis Sci 1999;76:363-9. [PubMed: 10416930]

11. Chung K, Mohidin N, O'Leary DJ. Undercorrection of myopia enhances rather than inhibits myopia progression. Vision Res 2002;42:2555-9. [PubMed: 12445849]

12. Leung JT, Brown B. Progression of myopia in Hong Kong Chinese schoolchildren is slowed by wearing progressive lenses. Optom Vis Sci 1999;76:346-54. [PubMed: 10416928]

13. Edwards MH, Li RW, Lam CS, Lew JK, Yu BS. The Hong Kong progressive lens myopia control study: study design and main findings. Invest Ophthalmol Vis Sci 2002;43:2852-8. [PubMed: 12202502]

14. Fulk GW, Cyert LA, Parker DE. A randomized trial of the effect of single-vision vs. bifocal lenses on myopia progression in children with esophoria. Optom Vis Sci 2000;77:395-401. [PubMed: 10966065]

15. Gwiazda J, Hyman L, Hussein M, Everett D, Norton TT, Kurtz D, Leske MC, Manny R, MarshTootle W, Scheiman M. A randomized clinical trial of progressive addition lenses versus single vision lenses on the progression of myopia in children. Invest Ophthalmol Vis Sci 2003;44:1492-500. [PubMed: 12657584]

16. Gwiazda JE, Hyman L, Norton TT, Hussein ME, Marsh-Tootle W, Manny R, Wang Y, Everett D. Accommodation and related risk factors associated with myopia progression and their interaction with treatment in COMET children. Invest Ophthalmol Vis Sci 2004;45:2143-51. [PubMed: 15223788]

17. Hasebe S, Ohtsuki H, Nonaka T, Nakatsuka C, Miyata M, Hamasaki I, Kimura S. Effect of progressive addition lenses on myopia progression in Japanese children: a prospective, randomized, doublemasked, crossover trial. Invest Ophthalmol Vis Sci 2008;49:2781-9. [PubMed: 18579755]

18. Perrigin J, Perrigin D, Quintero S, Grosvenor T. Silicone-acrylate contact lenses for myopia control: 3-year results. Optom Vis Sci 1990;67:764-9. [PubMed: 2247299]

19. Khoo CY, Chong J, Rajan U. A 3-year study on the effect of RGP contact lenses on myopic children. Singapore Med J 1999;40:230-7. [PubMed: 10487074]

20. Walline JJ, Jones LA, Mutti DO, Zadnik K. A randomized trial of the effects of rigid contact lenses on myopia progression. Arch Ophthalmol 2004;122:1760-6. [PubMed: 15596577]

21. Cho P, Cheung SW, Edwards M. The longitudinal orthokeratology research in children (LORIC) in Hong Kong: a pilot study on refractive changes and myopic control. Curr Eye Res 2005;30:71-80. [PubMed: 15875367]

22. Fulk GW, Cyert LA, Parker DE, West RW. The effect of changing from glasses to soft contact lenses on myopia progression in adolescents. Ophthalmic Physiol Opt 2003;23:71-7. [PubMed: 12535059]

23. Walline JJ, Jones LA, Sinnott L, Manny RE, Gaume A, Rah MJ, Chitkara M, Lyons S. A randomized trial of the effect of soft contact lenses on myopia progression in children. Invest Ophthalmol Vis Sci 2008;49:4702-6. [PubMed: 18566461]

24. Shih YF, Hsiao CK, Chen CJ, Chang CW, Hung PT, Lin LL. An intervention trial on efficacy of atropine and multi-focal glasses in controlling myopic progression. Acta Ophthalmol Scand 2001;79:233-6. [PubMed: 11401629] 
25. Chua WH, Balakrishnan V, Chan YH, Tong L, Ling Y, Quah BL, Tan D. Atropine for the treatment of childhood myopia. Ophthalmology 2006;113:2285-91. [PubMed: 16996612]

26. Tan DT, Lam DS, Chua WH, Shu-Ping DF, Crockett RS. One-year multicenter, double-masked, placebo-controlled, parallel safety and efficacy study of $2 \%$ pirenzepine ophthalmic gel in children with myopia. Ophthalmology 2005;112:84-91. [PubMed: 15629825]

27. Siatkowski RM, Cotter S, Miller JM, Scher CA, Crockett RS, Novack GD. Safety and efficacy of $2 \%$ pirenzepine ophthalmic gel in children with myopia: a 1-year, multicenter, double-masked, placebocontrolled parallel study. Arch Ophthalmol 2004;122:1667-74. [PubMed: 15534128]

28. Siatkowski RM, Cotter SA, Crockett RS, Miller JM, Novack GD, Zadnik K. Two-year multicenter, randomized, double-masked, placebo-controlled, parallel safety and efficacy study of $2 \%$ pirenzepine ophthalmic gel in children with myopia. J AAPOS 2008;12:332-9. [PubMed: 18359651]

29. Kurtz D, Hyman L, Gwiazda J, Manny R, Dong LM, Wang Y, Scheiman M, the COMET Group. Role of parental myopia in the progression of myopia and its interaction with treatment in COMET children. Invest Ophthalmol Vis Sci 2007;48:562-70. [PubMed: 17251451]

30. Hirsch MJ. Predictability of refraction at age 14 on the basis of testing at age 6--interim report from the Ojai Longitudinal Study of Refraction. Am J Optom Arch Am Acad Optom 1964;41:567-73. [PubMed: 14236561]

31. Zadnik K, Mutti DO, Friedman NE, Qualley PA, Jones LA, Qui P, Kim HS, Hsu JC, Moeschberger ML. Ocular predictors of the onset of juvenile myopia. Invest Ophthalmol Vis Sci 1999;40:193643. [PubMed: 10440246]

32. Smith EL 3rd, Ramamirtham R, Qiao-Grider Y, Hung LF, Huang J, Kee CS, Coats D, Paysse E. Effects of foveal ablation on emmetropization and form-deprivation myopia. Invest Ophthalmol Vis Sci 2007;48:3914-22. [PubMed: 17724167]

33. Rose KA, Morgan IG, Ip J, Kifley A, Huynh S, Smith W, Mitchell P. Outdoor activity reduces the prevalence of myopia in children. Ophthalmology 2008;115:1279-85. [PubMed: 18294691]

34. Rose KA, Morgan IG, Smith W, Burlutsky G, Mitchell P, Saw SM. Myopia, lifestyle, and schooling in students of Chinese ethnicity in Singapore and Sydney. Arch Ophthalmol 2008;126:527-30. [PubMed: 18413523]

35. Mutti DO, Mitchell GL, Moeschberger ML, Jones LA, Zadnik K. Parental myopia, near work, school achievement, and children's refractive error. Invest Ophthalmol Vis Sci 2002;43:3633-40. [PubMed: 12454029]

36. Jones LA, Sinnott LT, Mutti DO, Mitchell GL, Moeschberger ML, Zadnik K. Parental history of myopia, sports and outdoor activities, and future myopia. Invest Ophthalmol Vis Sci 2007;48:352432. [PubMed: 17652719] 


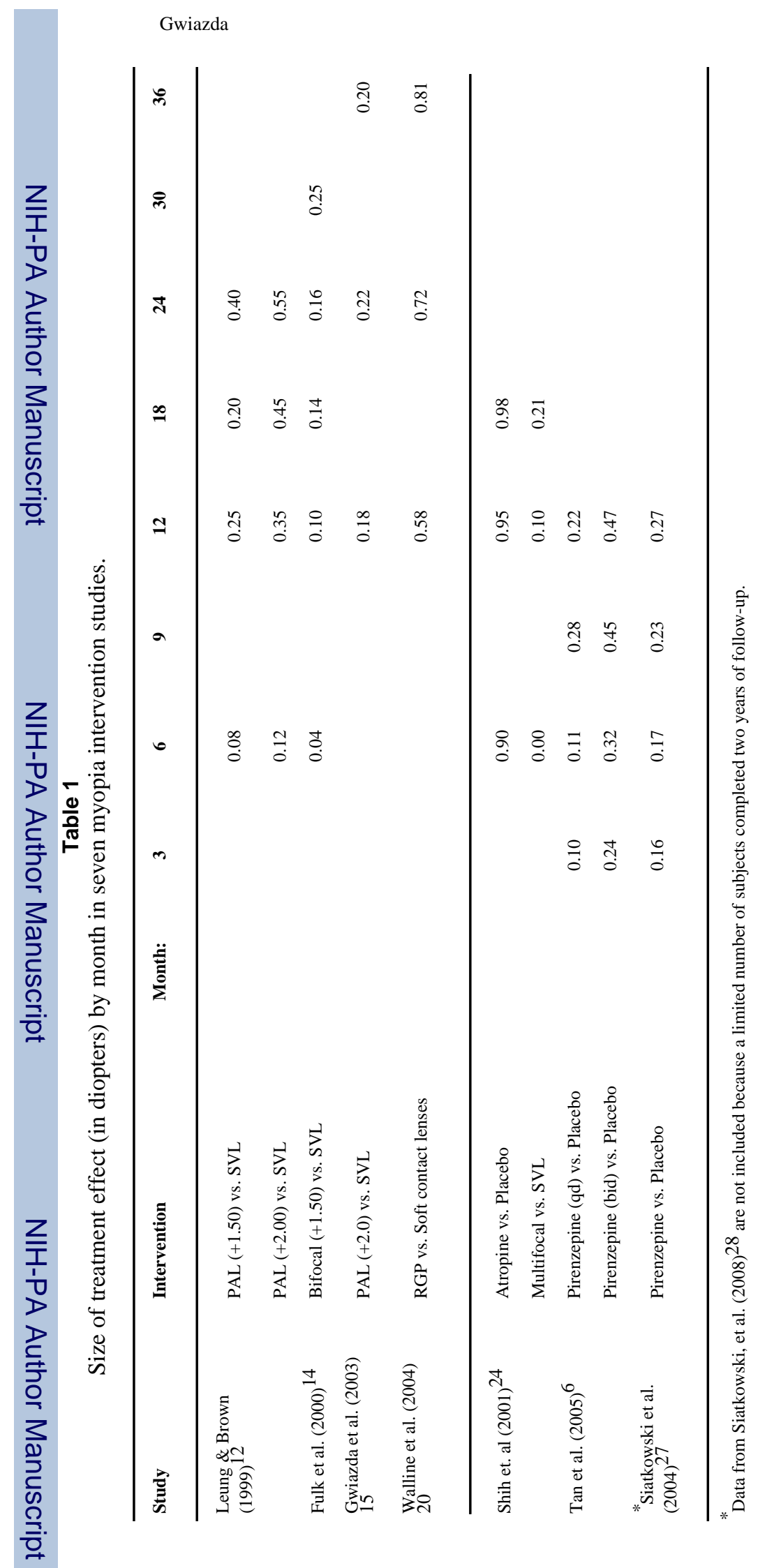

